\title{
Catalytic Asymmetric Geminal Difluorination of $\beta$-Substituted Styrenes
}

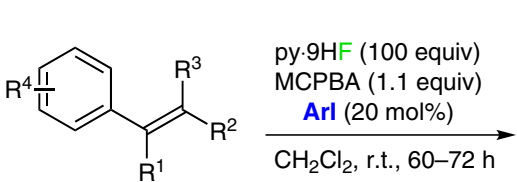

1

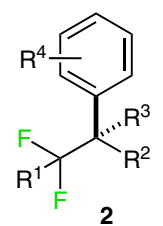

32 examples $28-93 \%$ yield er from $82: 18$ to $98.5: 1.5$

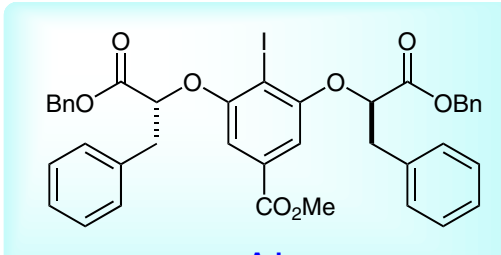

Arl
Category

Organo- and

Biocatalysis

\section{Key words}

fluorination

asymmetric catalysis

hypervalent iodine

phenonium ion intermediates

styrenes

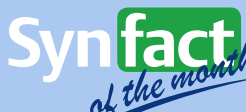

Proposed reaction mechanism:

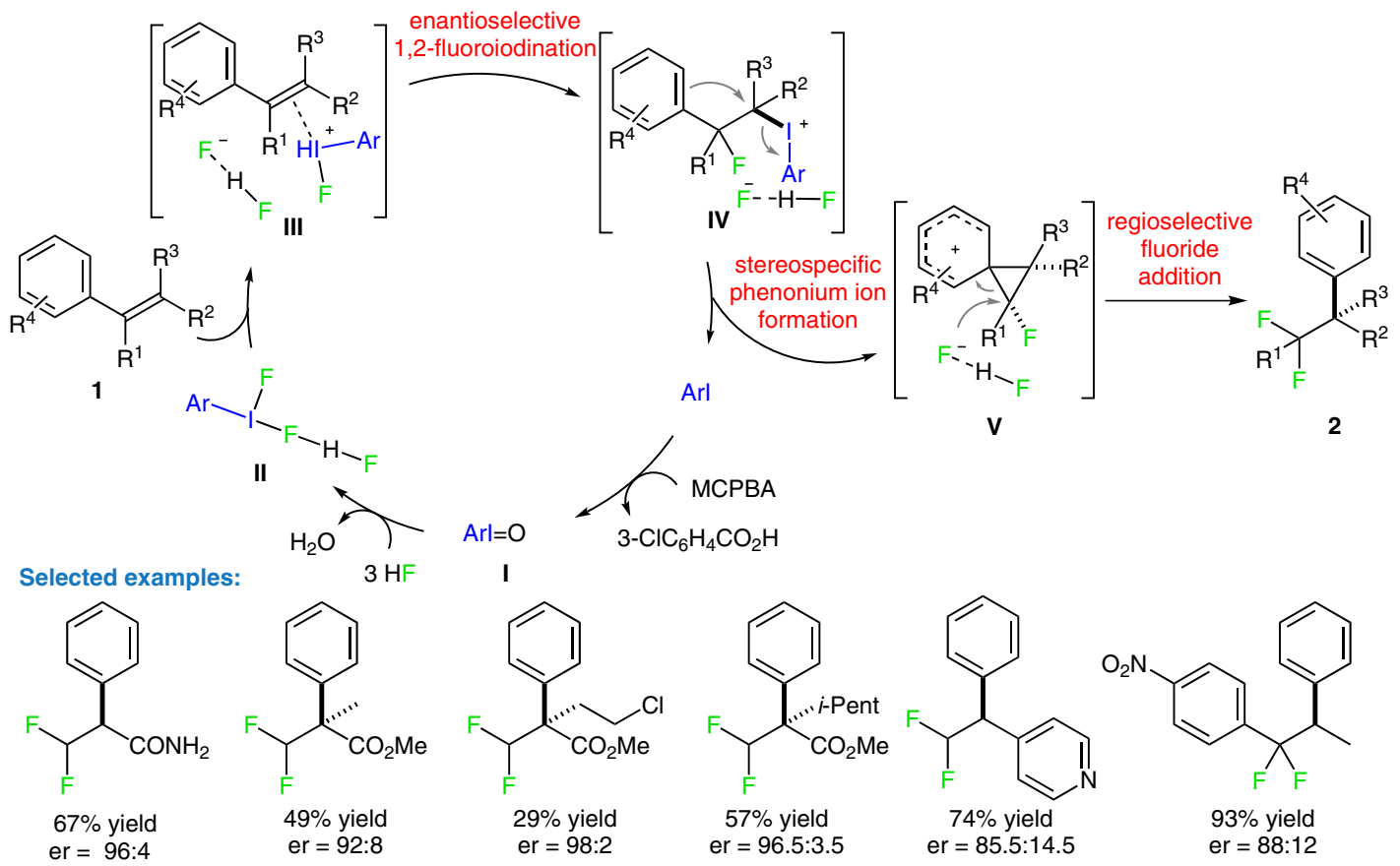
formation of $\beta$-substituted styrenes to form romethylated tertiary or quaternary stereocenters. The reaction starts with the oxidation of the aryl iodide catalyst to give iodoso arene $\mathbf{I}$, which reacts with HF to give hypervalent iodine intermediate II. The catalytic cycle proceeds with an enantioselective 1,2-fluoroiodination to give IV, followed by the stereospecific formation of phenonium ion $\mathbf{v}$. The final regioselective fluoride addition leads to product 2 in high yield and high enantioselectivity. SYNFACTS Contributors: Benjamin List, Francesca Mandrelli Synfacts 2016, 12(10), 1085 Published online: 19.09.2016 Dol: 10.1055/s-0036-1589174; Reg-No.: B05716SF
Comment: Geminal difluoro groups are important inert isosteres of polar functional groups such as alcohols and thiols. The authors recently reported a diastereoselective 1,2-difluorination of alkenes (J. Am. Chem. Soc. 2016, 138, 5000), which occurs through anchimeric assistance by a carbonyl group, whereas here the 1,1-difluorination is achieved through skeletal rearrangement via phenonium ion intermediate $\mathbf{v}$. 